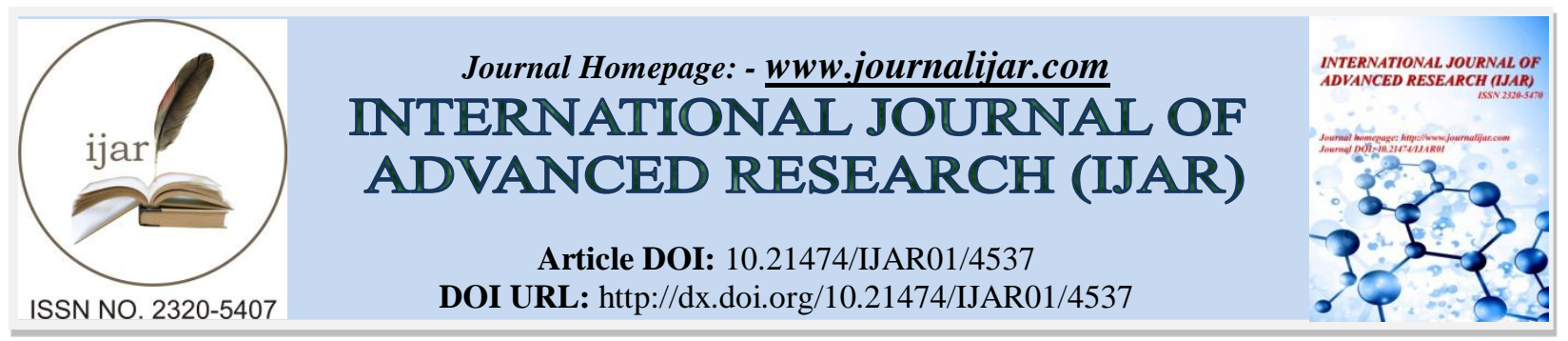

RESEARCH ARTICLE

\title{
DNA BARCODING AS A WILDLIFE FORENSIC TOOL (WFT) FOR SPECIES IDENTIFICATION: A CASE STUDY ON BLACKBUCK (ANTILOPE CERVICAPRA) IN INDIA.
}

\author{
Vikas Kumar ${ }^{1},{ }^{*}$ Neel kamal ${ }^{2}$ and Arun Sharma ${ }^{2}$. \\ 1. Forensic Science, Department of Genetics, M.D. University, Rohtak. \\ 2. Director, FSL Junga, Shimla, Himachal Pradesh, India.
}

\section{Manuscript Info}

..........................

Manuscript History

Received: 19 April 2017

Final Accepted: 21 May 2017

Published: June 2017

Key words:-

DNA barcoding, CO1 gene, Blackbuck, Wildlife Forensic Tool, Wildlife related crime

\section{Abstract}

This article reports a case study, where DNA barcoding technique uses mitochondrial cytochrome $\mathrm{C}$ oxidase subunit 1 (CO1) gene analysis that has been applied to suspected degraded animals for species identification to investigate a wildlife crime. In present case study, by comparing the query sequences with the reference sequences generated in the laboratory, reveals that the suspected degraded animal body was of Blackbuck (Antilope cervicapra). Results highlights the importance of the standardized short DNA fragment as a cost effective Wildlife Forensic Tool (WFT) in order to development of barcoding database from each country to assist in wildlife related crimes.

Copy Right, IJAR, 2017,. All rights reserved.

\section{Introduction:-}

Although the Government of India has protected the wildlife under the Wildlife (Protection) Act 1972 (Sahajpal et al., 2009) with the aim of effectively controlling the crime against wildlife. Identification of particular wildlife species is one of the essential and critical issues for wildlife investigative agencies. Wildlife forensic is a very broad discipline and investigative agencies have to deal with a plethora of species, which are protected or not protected by laws. The failure of our crime investigation system is mainly due to lack of reference materials and optimal authenticated genetic markers for many of the wildlife species, leading to the hampered identification results (Tobe and Linacre, 2010; Iyengar, 2014).

DNA barcoding (the standardized short DNA fragment) has been considered one of the most effective, powerful wildlife forensic tools (WFT) for species identification or to differentiate, even from degraded or processed pieces of biological materials (Hebert et. al., 2003; Ferri et.al., 2009; Kumar et.al., 2012). This technique having wide acceptance not just because of its reliability and validity of species identification, but also due to the universality of the same set of universal PCR primers for a broad taxon range of amplification and identification (Hebert and Gregory, 2005).

The advent of molecular techniques plays a crucial role in forensic casework. Molecular species identification is an attempt to compare an unknown biological sample to a known reference sample by matching sequences of genes (Ogden et. al., 2009; Johnson,et.al., 2014). In this case study, Cytochrome C oxidase subunit I (COI) region of the mitochondrial was used as DNA barcode gene and sequenced by using universal primers to identify the species of unknown samples. The introduction of DNA barcoding highlighted the expanding use of mitochondrial COI gene as a genetic marker, considered that the barcode sequence ideal for effective species identification (Iyengar, 2014; Hebert et al., 2003; Dawnay et. al., 2007; Linacre and Tobe, 2011). In the present study, mitochondrial COI 
sequencing was used to identify species to solve a wildlife offense involving Blackbuck (Antilope cervicapra). The partial sequences of COI gene are used for identification of species in the forensic investigation because it showed a high degree of sequence similarity to corresponding sequences in searching the database.

\section{Materials and Methods:-} Case History and Sample Collection:-

Hisar range, wildlife officer, wildlife department, Haryana forwarded a seized degraded body of an animal to the pathology department LUVAS University, Hisar for postmortem analysis to resolve animal identity, with a suspicion that a wildlife crime had been committed and suspected animal body must be a Blackbuck (Antilope cervicapra) (also known as an Indian antelope, is protected under schedule-I of the wildlife protection act of 1972) (Sahajpal et al., 2009). The study tissue sample was collected during the postmortem analysis and meanwhile two known blood samples of the Blackbuck as a reference samples were collected for comparative study from the Hisar deer park during a veterinary check-up, stored at $-20^{\circ} \mathrm{C}$ and $4^{\circ} \mathrm{C}$ respectively (Kumar and Neelkamal, 2015). Permission for this scientific research work and biological sample collection is granted by the MoEF\&CC (Ministry of Environment, Forest and Climate Change) (Wildlife Division) Government of India vide letter no 1-56/2016WL and by the Forest Department Haryana (wildlife division) 87/11-04-16 respectively.

DNA extraction, PCR amplification, and sequencing to Establish the Identity:-

Total genomic DNA was extracted from the collected biological samples within 10 days after collection. Tissue sample was chopped into fine small pieces and grind into the fine powder using liquid nitrogen. DNA extractions (from both tissue and blood) were performed using DNeasy blood and tissue Kit (Qiagen, Valencia, CA, USA) with the supplied reagents and protocol (with a little modification by enhancing cell lysis time to 3-4 hours).

All PCR amplifications of a portion of the mitochondrial COI gene were performed in a volume of $25 \mu$ of reaction PCR Buffer, $2.5 \mathrm{mM} \mathrm{MgCl2}, 0.2 \mathrm{mM}$ of each of dNTPs, $10 \mathrm{pM}$ each of forward and reverse primers LCO and $\mathrm{HCO}$ (Folmer et al. 1994) one units of AmpliTaq Gold polymerase (Applied Biosystems) and 30-40 ng of purified DNA. Amplification was carried out for an initial $5 \mathrm{~min}$ at $95^{\circ} \mathrm{C}$ followed by 35 cycles at $95^{\circ} \mathrm{C}, 54^{\circ} \mathrm{C}$, each for $45 \mathrm{sec}$ and $72^{\circ} \mathrm{C}$ for $1 \mathrm{~min}$, and a final elongation step for $7 \mathrm{~min}$ at $72^{\circ} \mathrm{C}$ in a Takara PCR System 9700 . The PCR products were confirmed in $1.2 \%$ agarose gel stained with ethidium bromide and obtained product were subjected to sequencing. These obtained PCR products were sequenced (Eurofins Genomics India) on both strands and results were checked, analyzed and edited in Chromas 2.4 (Technelysium Pty Ltd., South Brisbane, Australia.

\section{Results and Discussion:-}

The obtained partial sequences of the COI gene were blasted for similarity against non-redundant sequence database using NCBI-BLAST program (National Center for Biotechnology Information-Basic Local Alignment Search Tool) (Altschul et al., 1990; Johnson et. al., 2008; Dennis et. al., 2013). The sequences were aligned along with the help of the corresponding sequences of closely related species extractive from NCBI-GenBank database and reference sequences generated in the laboratory, were aligned and neighbor-joining (NJ) tree (with of the K2P distance model) was created using MEGA v7.0 software (Kumar et. al., 2016) and BioEdit v7.2.6 software(Hall, 2011).

The degree of sequence similarity search in NCBI database showing 99\% similarity with COI sequence of Blackbuck (Antilope cervicapra) (NCBI Accession no. KX012634.1 and KT372100.1) and showing 100\% sequence similarity with COI sequence of two known reference samples of Blackbuck generated in our laboratory. The generated COI sequences (Showing in Table 1) were aligned using BioEdit software. Figure 1 showed the phylogenetic tree $(\mathrm{NJ})$ based on the $\mathrm{CO} 1$ sequences using the reference sequence, query sequences and sequences of closely related species obtained from the NCBI GenBank database

The results clearly conclude that mitochondrial COI gene sequences can forensically differentiate Blackbuck with other related species. With these results we confidently evident that in the present study, the forensic sample are that of Blackbuck (Antilope cervicapra) which is Schedule I animal, protected under the Wildlife (Protection) Act 1972, Government of India.

Table 1: Showing the alignment of COI gene sequence (align the Query, reference and NCBI reference database sequences) using the BioEdit software. Each dot '. ' in the aligned sequence indicates the identical nucleotide base $(\mathrm{G}, \mathrm{C}, \mathrm{A}, \mathrm{T})$ to the one at the corresponding position in the sequence of Query and the position of ' $\mathrm{A}$ ', ' $\mathrm{G}$ ', ' $\mathrm{C}$ ' ' $\mathrm{T}$ ' indicates the sequence differences between the aligned samples. 


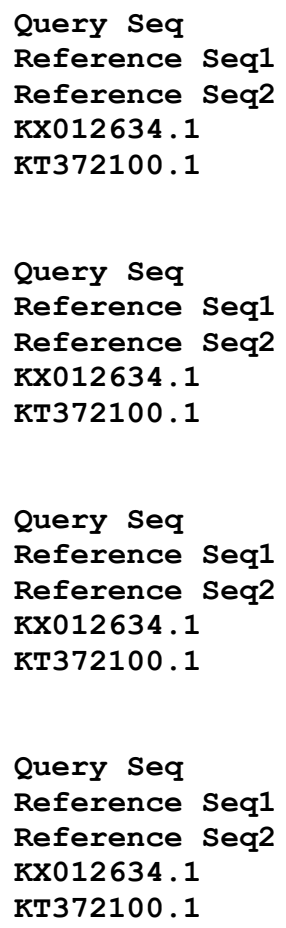

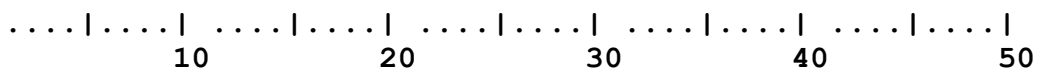

GGTTGTATTT AGGTTTCGGT CTGTTAGAAG TATTGTAATG CCAGCAGCTA

$\ldots \ldots \ldots \ldots \ldots \ldots \ldots \ldots \ldots \ldots \ldots \ldots \ldots \ldots \ldots \ldots \ldots \ldots$

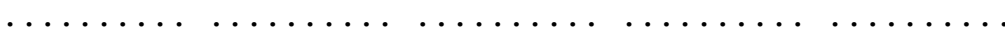

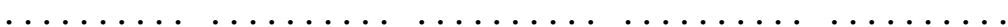

$\left.\cdots|\cdots|_{60} \ldots|\cdots|_{70} \ldots|\cdots|_{80} \cdots|\cdots|_{90} \cdots|\cdots|\right|_{100}$

GTACAGGAAG TGAAAGGAGT AGAAGTACGG CGGTAATTAA AACAGATCAC

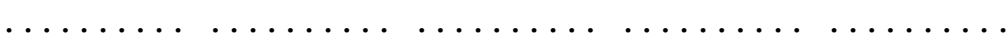

$\ldots \ldots \ldots \ldots \ldots \ldots \ldots \ldots \ldots \ldots \ldots \ldots \ldots \ldots \ldots \ldots \ldots \ldots \ldots$

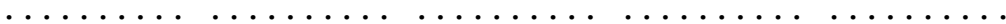

$\ldots|\ldots| \ldots|\ldots| \ldots|\ldots| \ldots|\ldots| \ldots|\ldots| \ldots|\ldots| \ldots \mid$

$\begin{array}{ccccc}110 & 120 & 130 & 140 & 150 \\ \text { ACAAATAGAG } & \text { GGGTTTGATA } & \text { TTGCGATATT } & \text { GCGGGAGGTT } & \text { TTATATTAAT }\end{array}$

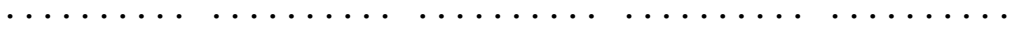

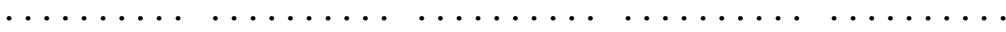

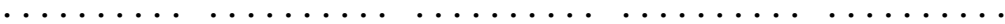

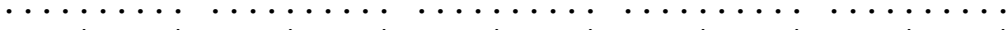

$\cdots||_{160} \ldots|\cdots|_{170} \ldots|\cdots|_{180} \ldots|\cdots|_{190} \ldots|\cdots|_{200}$

AATTGTTGTA ATAAAGTTAA TGGCACCTAA GATTGAGGAG ACACCTGCCA

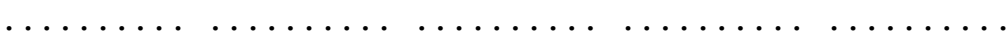

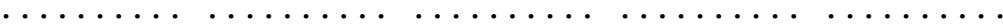
$\ldots\left|\cdots l_{210} \ldots\right| \cdots l_{220} \ldots\left|\cdots l_{230} \ldots\right| \cdots l_{240} \ldots \mid \cdots l_{1}$

GGTGAAGAGA GAAGATGGTT AGATCTACTG AAGCACCTGC GTGGGCCAGG

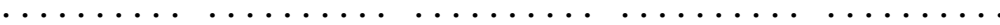

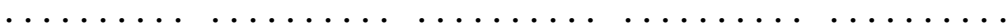

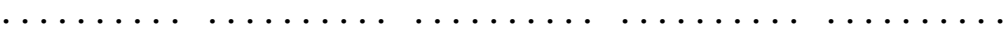

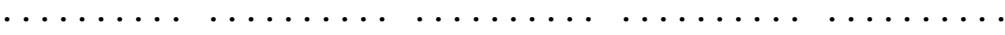

$\cdots|\cdots|_{260} \ldots|\cdots|_{270} \ldots|\cdots|_{280} \ldots|\cdots|_{290} \cdots \mid \cdots l_{300}$

TTGCCCGCTA GAGGAGGGTA TACGGTTCAG CCTGTCCCTG CTCCTGCTTC

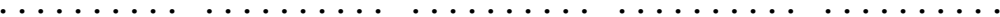

.

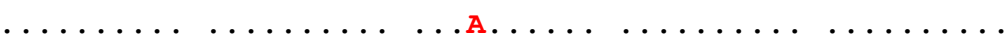
$\cdots|\cdots|_{310} \ldots|\cdots|_{320} \ldots|\cdots|_{330} \ldots|\cdots|_{340} \ldots|\cdots|_{350}$

AACTATAGAA GATGCTAGgA GCAATAGAAA AGAGgGAgGg AGAAgTCAgA

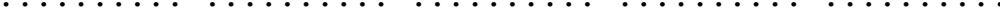

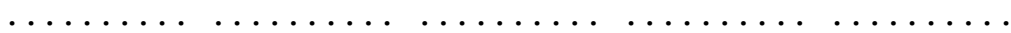

$\ldots \ldots \ldots \ldots \ldots \ldots \ldots$ T. $\ldots \ldots \ldots \ldots \ldots \ldots$

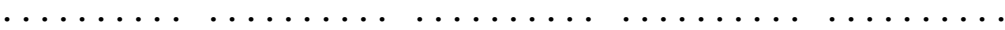

$\cdots|\cdots|_{360} \cdots|\cdots|_{370} \cdots|\cdots|_{380} \cdots|\cdots|_{390} \cdots \mid \cdots 1_{400}$

AGCTCATGTT GTTTATTCGG GGGAATGCTA TGTCGGGAGC GCCAATTATT

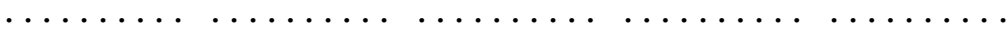

$\ldots \ldots \ldots \ldots \ldots \ldots \ldots \ldots \ldots \ldots \ldots \ldots \ldots \ldots \ldots$

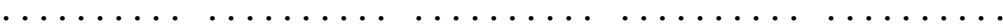

$\cdots|\cdots|_{410} \ldots|\cdots|_{420} \ldots|\cdots|_{430} \ldots|\cdots|_{440} \ldots|\cdots|_{450}$

AGGGGGACTA GTCAATTGCC AAATCCTCCG ATTATAATAG GTATTACTAT

$\cdots \ldots \ldots \ldots$

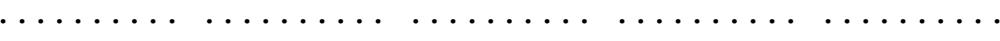



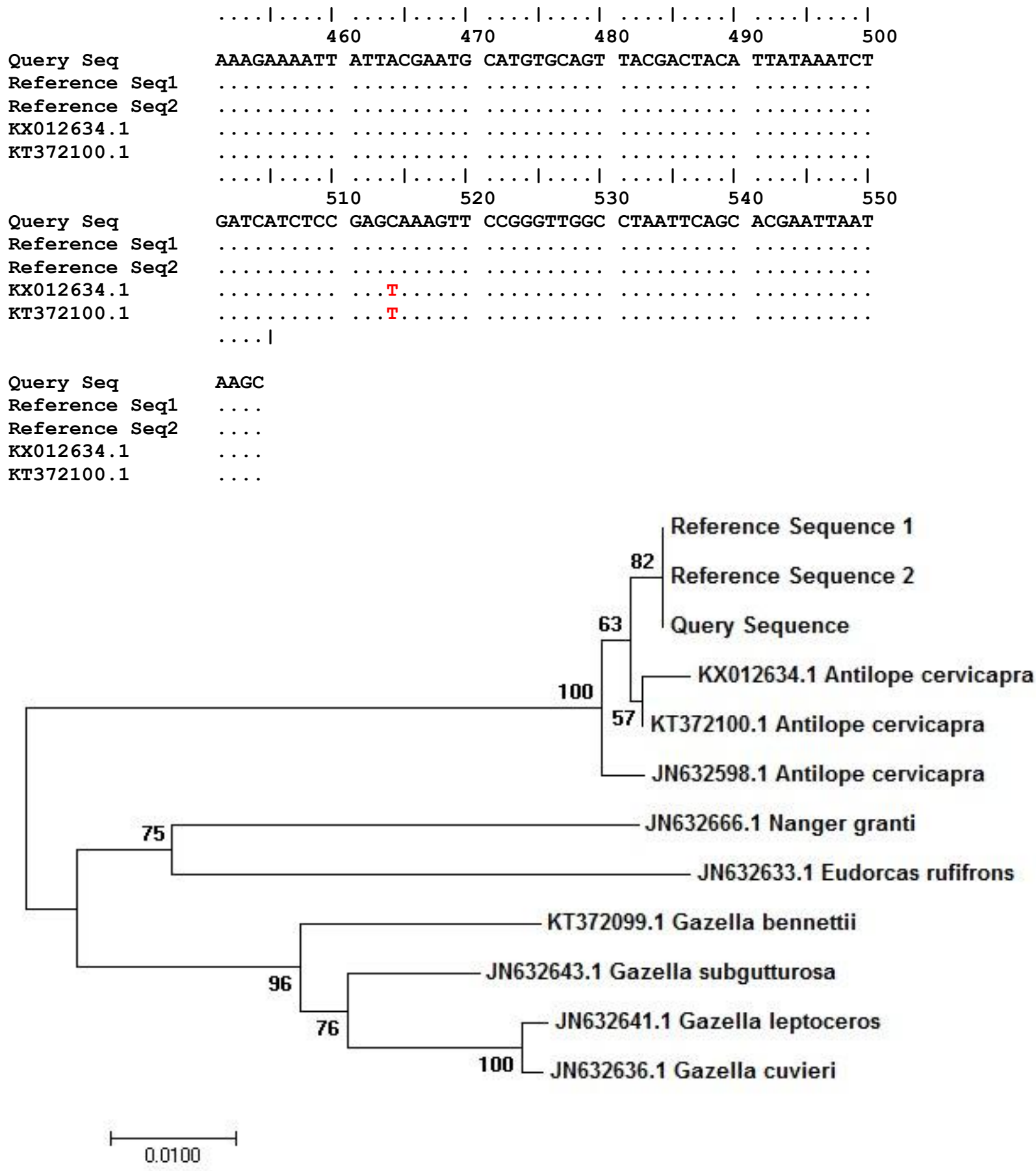

Figure 1:- Showing phylogenetic tree analysis (K2P model -Neighbor-Joining method) using COI gene sequence.

\section{Discussion and Conclusion:-}

Various studies have proved and validated the importance of DNA barcoding COI gene as a molecular forensic technique for the application in species identification (Hebert and Gregory, 2005; Linacre and Tobe, 2011; Dalton and Kotze, 2011). Whereas, validity and accuracy of this method highly rely on the submitted database data quality, misidentification, leads to wrong interpretation (Kumar et al., 2012). In this study, we use localized reference datasets to eliminate misinterpretation. The output of the present investigative study demonstrates that the question forensic sample is that of the Blackbuck, which might help to the investigative agencies to solve the case. 
Results highlights the importance of DNA barcoding (the standardized short DNA fragment) as a valuable cost effective powerful wildlife forensic tool (WFT) for the identification of the wildlife species. And also emphasizing the need of accurate wildlife reference material from each country in order to convict wildlife cases and to support in the development and expansion of comprehensive wildlife reference barcoding databases to assist with future forensic investigations (Dalton and Kotze, 2011). The partial sequences for COI gene generated from the present study were submitted to the NCBI GenBank and Bold (Barcode of life database) database system vide Accession No. KX524519.1 and KABIR001-17 respectively.

\section{Acknowledgements:-}

We would like to thank the Department of MOEF \&CC (Wildlife Division) Government of India and Department of Forest (Wildlife Division) Haryana, for giving me permission for sample collection. We also thanks to the staff of the pathology department LUVAS University, Hisar for providing postmortem samples for analysis. And also sincerely thankful to University Grant Commission for providing financial support (by providing UGC-SRF fellowship).

\section{Disclosure statement:-}

The author's report contains no conflicts of interest. The authors alone are responsible for the content and writing of this article.

\section{References:-}

1. Altschul, S.F., Gish, W., Miller, W., Myers, E.W., Lipman, D.J. (1990): Basic local alignment search tool. J. Mol. Biol., 215: 403-410.

2. Dalton, D.L. and Kotze, A. (2011): DNA barcoding as a tool for species identification in three forensic wildlife cases in South Africa. Forensic Sci. Int., 207(1-3): e51-e54.

3. Dawnay, N., Ogden, R., McEwing. R., Carvalho, G.R., et al. (2007): Validation of the barcoding gene COI for use in forensic genetic species identification. Forensic Sci. Int., 173:1-6.

4. Dennis A. Benson, Mark Cavanaugh, Karen Clark, Ilene Karsch-Mizrachi, David J. Lipman, James Ostell, Eric W. Sayers. (2013): GenBank. Nucleic Acids Res., 41(D1): D36-D42.

5. Ferri, G., Alu, M., Corradini, B., Licata, M. and Beduschi, G.,(2009): Species identification through DNA 'barcodes'. Genet. Test Mol. Biomark., 13: 421-426

6. Folmer, O., Black, M., Hoeh, W., Lutz, R., Vrijenhoek, R. (1994): DNA primers for amplification of mitochondrial cytochrome c oxidase subunit I from diverse metazoan invertebrates. Mol. Mar. Biol. Biotechnol., 3:294-299.

7. Hall, T. (2011): BioEdit: an important software for molecular biology. GERF. Bull. Biosci., 2(1): 60-61.

8. Hebert, P.D. and Gregory, T.R. (2005): The promise of DNA barcoding for taxonomy. Systematic biology., 54(5): 852-859.

9. Hebert, P.D., Cywinska, A., Ball, S.L. and deWaard, J.R. (2003): Biological identifications through DNA barcodes. Proc. R. Soc. Lond. B Biol. Sci., 270: 313-321.

10. Iyengar, A. (2014): Forensic DNA analysis for animal protection and biodiversity conservation: A review. J. for Nature Conser., 22(3): 195-205.

11. Johnson, M., Zaretskaya, I., Raytselis, Y., Merezhuk, Y., McGinnis, S., and Madden, T.L. (2008): NCBI BLAST: a better web interface. Nucleic acids research., 36(suppl 2): W5-W9.

12. Johnson, R.N., Wilson-Wilde, L., and Linacre, A. (2014): Current and future directions of DNA in wildlife forensic science. Forensic Sci. Int. Genet., 10:1-11.

13. Kumar, S., Stecher, G. and Tamura, K. (2016): MEGA7: Molecular Evolutionary Genetics Analysis Version 7.0 for Bigger Datasets. Mol. Biol. Evol., 33(7):1870-1874.

14. Kumar, U.S., Ratheesh, R.V., Thomas, G. and George, S. (2012): Use of DNA barcoding in wildlife forensics: A study of sambar deer (Rusa unicolor). Forest Sci. and Technology., 8(4): 224-226.

15. Kumar, V. and Neelkamal. (2015): Wildlife DNA Evidence: Recognition, Collection and Preservation. Res. J. Forensic Sci., 3(7): 8-15.

16. Linacre, A., and Tobe, S.S. (2011): An overview to the investigative approach to species testing in wildlife forensic science. Investigative Genet., 2: 2-9.

17. Ogden, R., Dawnay, N. and McEwing, R. (2009): Wildlife DNA forensics - bridging the gap between conservation genetics and law enforcement. Endangered Species Research., 9(3): 179-195.

18. Sahajpal, V., Goyal, S.P., Thakar, M.K., and Jayapal, R. (2009): Microscopic hair characteristics of a few bovid species listed under Schedule-I of Wildlife (Protection) Act 1972 of India. Forensic Sci. Int., 89(1): 34-45.

19. Tobe, S.S. and Linacre, A. (2010): DNA typing in wildlife crime: recent developments in species identification. Forensic Sci. Med. Pathol., 6:195-206. 